\title{
Cultural power in Chinese higher education institutions: Its definition and dimensions
}

\author{
Jun Lu ${ }^{1}$, Hongqing Heng ${ }^{2}$, Yang Yang ${ }^{3}$ \\ Public Administration Department, School of Humanity and Social Science \\ Beijing Institute of Petrochemical Technology (BIPT) \\ Beijing, People's Republic of China \\ ${ }^{1}$ lujun@bipt.edu.cn, ${ }^{2}$ henghongqing@bipt.edu.cn, ${ }^{3}$ yangyang1993@bipt.edu.cn
}

\begin{abstract}
Colleges in China enjoy the reputation as the light of the society in that they are the important source of power pushing social development and human civilization progress. As well, college is the location in which cultural power exists and disseminates. Literatures since 1990s with regard to topics in cultural power and its impacts in modern Chinese higher education institutions (i.e. four-year colleges) were identified in China Knowledge Resource Integrated Database (CNKI). By reviewing these works, we concluded that collegiate cultural power is fostered in certain social and historical environment as well as in the process of establishing college, and it plays a significant role in developing college, boosting regional development, and impelling social progress. In addition, we broke collegiate cultural power down into four dimensions, and internal relationships among four dimensions were examined in the end, aiming at facilitating understanding of how four dimensions interact with each other.
\end{abstract}

Keywords-cultural power; Chinese colleges; concept; dimensions

\section{INTRODUCTION}

Higher education in China has completed shifts toward mass education from elite education, and has been making endeavors to broaden the population of beneficiary. With the development and prosperity of Chinese higher education, connections between local colleges and the districts are tightening much closer than before. By 2008, China has already established 2,263 higher education institutions (referring to four-year colleges in this study), of which 95 percent of colleges are municipal- or provincial-based by nature. It was estimated that over 80 percent of students graduated from those colleges have the opportunity to be offered a job right in the city or province, which the college locate in. More important, these high-caliber students trained with specialized knowledge have become the crucial resource for enterprises and local government to compete against each other in contemporary society.

Knowledge-based economy brings closer relationship between institutes and society [1]. Therefore, intelligence and knowledge are the foremost impetus for social and economic development, the origin of scientific research, knowledge innovation, and technological invention, as well as the source of nurturing talents and elites. As Zhou [2] suggested, college is the light of society and the power of leading development in human civilization, as well as where exactly cultural power exist. In other words, through potential impacts of collegiate cultural power on innovative knowledge, pioneering technology, and outstanding talents, it directly facilitates economic development and societal progress.

Cultural power radiated from vehicle of higher education institutions has been playing an increasingly important role in local or regional economy and society, especially, for example, in arenas of talent training, scientific research, and social services. On the one hand, under the influence of collegiate cultural power, labors are trained to be higher quality and more qualified for job tasks (for example, acquiring new skills, obtaining management knowledge), resulting in increased productivity and efficiency, which in turn pushes faster development in local economy. On the other hand, colleges, as the center point, offers the most advanced technology and theories to companies and governments (such as petroleum and societal administration), which greatly helps drive prosperity in society and relevant industries.

In Chinses academia, collegiate cultural power has been drawing researchers' attention since the introduction of its concept [3]. Many studies were carried out in the utility of case study method from empirical perspective, while other studies put their emphasis on construct and strengthen conceptual and theoretical frameworks. There is, however, no such research concluding results from both empiricism and theoreticalism to provide a broader picture and better understanding of research on collegiate cultural power and its impacts. Given the importance of collegiate cultural power and lack of overview, we examined and synthesized literatures with regard to topics of cultural power in Chinese colleges and its impact since 1990s, expecting that commonalities and differences could be identified and concluded for future research in this arena.

\section{LITERATURE REVIEW}

\section{A. Concept of Cultural Power}

The word Cultural Power was first utilized in the book The Economy and the Culture written by Nawa Taro, a Japanese researcher. Afterwards, the notable American economist Lester C. Thurow, demonstrated explicitly the cultural power and 
suggested that economic competition in twentieth-first century, to some extent, would depend on the race of cultural power. In China, Jia first introduced the concept of cultural power and suggested cultural power is comprised of intelligence factor, spiritual power, cultural network, and traditional culture. Furthermore, he predicted that cultural power would be the impetus for development of modern market economy [4, 5]. Since then, cultural power gained much popularity and drew extensive attention to researches in Chinese academia. Kong [6] defined cultural power as the influence of certain cultural spirits with certain cultural impacts and characteristics on people. This definition stressed the proactive impact of cultural power on people. In addition, Zhou [7] proposed that cultural power represents competitiveness and productivity in socioeconomic development, especially for development in the enterprises. While Cao, taking a broader perspective, defined cultural power as the real force formed by cultural development and accumulation in a country or region, and its influence on economics, politics, society, and every aspect of life related to human beings. When research on this topic goes further, the role which cultural power is playing in national comprehensive power will be more significant, and will gradually become vitally core force to promote social and economic development $[8,9]$.

\section{B. Concept of Collegiate Cultural Power}

In education arena, culture power is acting as a powerful impetus for colleges to progress and develop. Meanwhile, education is in turn becoming the vehicle of cultural power to develop and disseminate, so that it can facilitate progress and development in society [10, 11]. Yu [3] proposed the notion of collegiate cultural power a decade ago, which later aroused widespread interest of researchers and educators.

There are three mainstreams of collegiate cultural power with regard to definition. One category defines that collegiate cultural power is both the core and an essential component of soft power for colleges $[12,13]$. The source of this power is cultural accumulation and innovation commonly accepted and shared by professors and students in the course of establishing a college. Such cultural power functions as the ability for college to keep pace with the times, to continuously create and invent, and to lead societal progress. The second definition regards collegiate cultural power as an integrated force generated by cultural factors on colleges and their members (i.e. professors, staffs, and students) as well as the public. Collegiate cultural power is also a dynamic cultural pattern with characteristics of accumulative, orientated, and promotive [14-16]. The third definition utilizes the concept of force in physics and draws several pairs of analogies between forces and collegiate cultural power [3, 17]. The spiritual culture is regarded to be point of action of collegiate culture power. Cultural wealth generated by members in the organization is applied force. While opinions and integrated appraisal by organizational members and the public are frictional force. Moreover, the direction of force towards people. In other words, there exist a bidirectional function between people and power - collegiate cultural power have influence on people, and people in that cultural reversely give pressure to collegiate cultural power.
Although three strands of perspective on collegiate cultural power demonstrate different concepts and express different emphasis on illustrating concepts, they reach a consensus that spiritual culture is the core of collegiate cultural power $[1,12$, $16,18,19]$.

\section{Dimensions of Collegiate Cultural Power}

Given three main concepts of collegiate cultural power, efforts to divide collegiate cultural power are aimed at having a better understanding of dimensions that constitute the concept. From cultural morphological perspective, collegiate cultural power is composed of four dimensions - physical cultural power, institutional cultural power, behavioral cultural power, and psychological cultural power [20]. Li [12] divided collegiate into four dimensions including spiritual cultural power, physical cultural power, intuitional cultural power, and behavioral cultural power. It is evident that $\mathrm{Li} \mathrm{[12]} \mathrm{and} \mathrm{He}$ [1] in all likelihood took the same perspective although Li did not clarify the perspective he took in his work three in four dimensions are remain the same. From cultural ecological perspective, collegiate cultural power can break down to five dimensions that include cultural cohesion force, cultural heritage force, cultural innovation force, cultural radiation force, and cultural education force [1]. Wang [19] suggested spiritual force, strategic force, imaginary force, and behavioral force are four core dimensions of collegiate culture power. Chen [11], similarly, recommended that collegiate cultural power should include oriented force, cohesive force, infectious force, and imaginary force. While $\mathrm{Ju}$ [17] regarded three dimensions related to higher education including morality, thinking, and innovation constitute collegiate cultural power. Additionally, Ding [21] proposed that cultural power of scientific research is the core of elevating collegiate cultural power.

\section{Effects of Collegiate Cultural Power}

Collegiate cultural power, as an essential source and component of college competitive force, directs college's inner construction, as well as functioning in social, economic, and cultural development [22]. With regard to internal effects, collegiate cultural power works on thoughts, emotions, and souls of professors and students, impacts student growth path and orientation, enhances cultural quality and cultural appreciation, and provides primitive impetus and supports for sustainable development $[15,16,23]$. In addition, the power functions on college construction and development, college orientation and strategic goals, college reputation and popularity, and college inner cohesion and core competitiveness $[3,16]$. In terms of external effects, collegiate cultural power facilitates economic prosperity and elevates the level of social civilization through ways of cultivating and supplying qualified talents, innovating and applying knowledge, and advancing and developing science and technology [2, 16, 22]. Otherwise, college spirits and cultural formation with history accumulation can become cornerstone to lead societal culture, and have irreplaceable innovative function in escalating national culture $[15,16,24]$. 


\section{E. Summary of Literature Review}

In summary, although studies on constructing collegiate cultural power has not been full-fledged enough to form an independent research area, previous literatures so far has expanded the scope and interest of research to large extent. However, these pieces of works revealed inequality in theoretical research and empirical research. In terms of number of literatures published in this topic, researches showed more preference and emphasis on theoretical development rather than verifying theories through empirical methods. Various perspective and theories are utilized to construct concept and dimensions of collegiate cultural power, while, by comparison, merely several pieces of work were studies on the basis of practical case. Therefore, validity and reliability need to be tested on current theory framework because of few empirical supports.

\section{ReConstructing Collegiate Cultural Power}

\section{A. Concept of Collegiate Culture Power}

Based on aforementioned literatures, we concluded that collegiate cultural power refers to the power of culture in college. The power is both spiritual influence force and physical promotion force cultivated in certain social and historical environment and in the practice of establishing college, which can lead college's self-construction, facilitate regional development and push society towards future progress.

\section{B. Dimensions of Collegiate Culture Power}

The formation of collegiate cultural power is not only build on colleges' traditions and history but also influenced by fast development of social development. Through synthesizing dimensions suggested by previous research, we proposed that collegiate cultural power can be broke down into four correlational dimensions, including image radiation force, spiritual cohesion force, behavioral orientation force, and research innovation force. Further demonstrations are given below for collegiate cultural power.

\section{1) Image radiation force.}

The first dimension is image radiation force. It is defined as the influence of college's image on the public and society. College's image is the overall appraisal and impression given by the public. In other words, the image should be the best reflection of college's comprehensive strength, overall competitiveness, and public affection. Essential factors such as educational environment, educational quality, and professors' reputation are what colleges radiate to the public in order to establish good images and social reputations.

\section{2) Spiritual cohesion force.}

The second dimension of collegiate cultural power is spiritual cohesion force. It contains philosophy accumulated in the long process of college practice and development, which is internalized into each member in the college. The force reflects powerful cohesion and attractiveness that create family-like harmonious atmosphere in college and impact people who live in and study on campus. As time passes, the force and the atmosphere it creates will contribute to professors and students' sense of identity and belonging, which in turn unifies and merged college members' ambitions, philosophy, and goals into a broader level of college practice and development. Only by this means can the college generate such powerful cohesion aforementioned. In other words, a college's philosophy, values, moral, atmosphere, or even institutions can resonate with professors and students at ideological and spiritual level. This kind of spiritual empathy contributes to bond professors and students into a unit with powerful force.

\section{3) Behavioral orientation force.}

The third dimension of collegiate cultural power is behavioral orientation force. It means the behavioral orientation, tendency, and expectation that college culture establishes in order to have a significant influence on college members' work, study, and life. The force moderates what and how members act and say though praising behaviors in accordance with expected values and philosophy and correcting, not punishing, actions performing against expectations. Under the instruction with evident orientation, members will have more favorable behaviors that follows what they are expected to do. From the perspective of education, behavioral orientation is another function of higher education, given other two functions of knowledge acquisition and skill cultivation. This orientation function (or force) keeps college members staying on the normal trace where college and its culture expect.

\section{4) Research innovation force.}

As the academic palace with active thinking and great innovation, colleges burden the responsibility of important task to create, disseminate, and apply knowledge to society. They are the source of new ideas, new cultures, and new knowledge, as well as the cradle of cultivating high-caliber talents. Only through continuously research innovation can colleges keep up with the rhythm of times and society. Liberal education in higher education aims at making solid foundation in basic knowledge, while major education practices students' minds and widens their abilities. Through a series of educational cultivation, students establish new ways of thinking, create new ideas, and propose new theories, which fundamentally elevate research innovation ability of colleges. On the other hand, research innovation force also embodies in social progress and economic development by applying new technologies and theories into practice.

\section{Inner Connections among Four Dimensions}

Four dimensions of collegiate cultural power are the best embodiment of the concept. Although they respectively play different role in constructing the concept, they are connected with each other internally as well. As shown in Figure 1, image radiation force is the foundation, spiritual cohesion force is the guarantee, behavioral orientation force is the direction, and research innovation force is the core. 


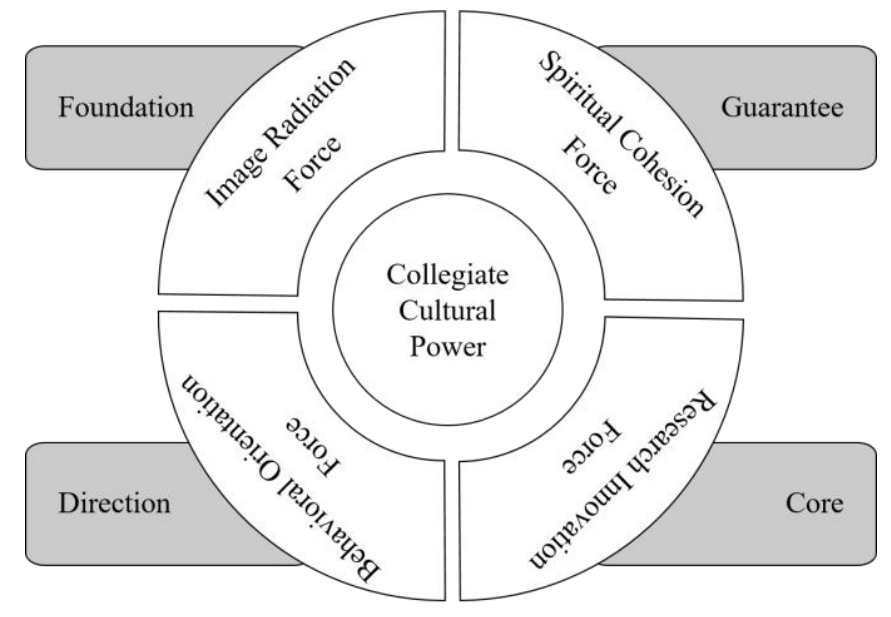

Fig. 1. Four dimensions of collegiate cultural power, in which image radiation force is the foundation, spiritual cohesion force is the guarantee, behavioral orientation force is the direction, and research innovation force is the core.

Image radiation force is always playing an influential role in three other dimensions because the establishment and development of spiritual cohesion force, behavioral orientation force, and research innovation force cannot be separated from this foundation. Only on the basis of that do three other dimensions enlarge their influence from college members to the public. Spiritual cohesion force is the ideological and spiritual guarantee of colleges with significant status. In other words, this dimension offers guarantee to collegiate cultural power at psychological and ideological levels, and provides image radiation force, behavioral orientation force, and research innovation force with conceptual and ideological guidance. Behavioral orientation force is the practical direction and code of conduct for collegiate cultural power. The behavioral dimension makes the clear pathway for image radiation force, spiritual cohesion force, and research innovation force to develop in their own ways. Research innovation force is the best embodiments of core values of collegiate cultural power in that the research results and applications reflect the development level of three other dimensions. In collegiate cultural power, image radiation force, spiritual cohesion force, behavioral orientation force, and research innovation force are coexisted and interdependent, and they facilitate and improve the conceptual construction of collegiate cultural power.

\section{CONCLUSION AND DISCUSSION}

Scrutinizing throughout history and contemporary, colleges have always been the most active place where brains and thoughts crash and collide. Many advanced ideas, concepts, and theories burst from the college, and make their endeavor to impact and change human world. These new thoughts and theories can not only promote academic research but also facilitate S\&T development and innovation. The application of these technologies and ideas truly boosts economic prosperity and societal progress. On the other hand, higher education institutions is where talents and elites get cultivated. Through various vehicles of education and training, colleges has provided and has been going to provide more qualified talents which directly participate in the construction and development of the society.

\section{REFERENCES}

[1] Q. Hu. On the cultural power on modern universities from the perspective of cultural ecology. Higher Education of Science, 2010, vol. 5, pp. 36-41 (In Chinese).

[2] X. X. Zhou. Discussion on the cultural power of universities. Journal of Nantong University (Education Sciences Edition), 2007, vol. 23(1), pp.41-43 (In Chinese).

[3] Z. R. Yu. Analysis on the competitiveness efficiency of collegiate cultural power. Journal of Dongbei University of Finance and Economics, 2004, vol. 11(3), pp. 89-91 (In Chinese).

[4] C. F. Jia. Cultural power. Beijing, China: People's Publication, 1995 (In Chinese).

[5] C. F. Jia \& W. L. Huang. Cultural power: Inner driver of market economic development. Letter of Science and Technology, 1995, vol. 12, pp. 18-22 (In Chinese).

[6] X. J. Kong. Discussion on the status of cultural power in knowledgebased economics. Qilu Journal, 1999, vol. 05, pp. 97-101 (In Chinese)

[7] Y. B. Zhou. Disscussion on cultural power. Journal of Hunan Normal University (Social Sciences Edition), 2003, vol. 5: 101-104 (In Chinese)

[8] Z. G. Zhou. On the constitution of cultural power and its position and function in the comprehensive national power. Journal of Changde Normal University (Social Science Edition), 2003, vol. 23(2), pp. 60-62 (In Chinese).

[9] B. P. Gu. On cultural power and social development. Theory Advancement, 2005, vol. 11(2), pp. 12-14 (In Chinese).

[10] S. H. Jin. Education and cultural power. Academic Research, 1996, (5), pp.21-24 (In Chinese).

[11] C. X. Chen. Collegiate cultural power and college development. Modern Education Science, 2009, (5), pp. 20-22 (In Chinese).

[12] H. S. Li. On the soft strength of university. Tsinghua Journal of Education, 2005, vol. 26(4), pp. 48-54 (In Chinese).

[13] Senior Professor Association. Discussion on collegiate cultural power and its mechanism. Higher Education and Economy, 2010, vol. 23(4), pp. 33-36 (In Chinese).

[14] X. H. Xu. On the effect of collegiate cultural power in college ideological education practice. Journal of Hubei University (Philosophy and Social Science), 2011, vol. 38(1), pp. 72-76 (In Chinese).

[15] S. Li \& T. Z. Wang. Analysis on the effect of collegiate cultural power on college students' ideological and moral education. Party Building and Ideological Education in School, 2011, (4), pp. 60-62 (In Chinese).

[16] G. X. Liu \& C. X. Wang. On the characteristics and functions of collegiate cultural power. Journal of Hubei University, 2011, vol. 38(1), pp. 68-71 (In Chinese).

[17] J. F. Ju \& C. C. Dong. Research on the function of higher education: Analysis in cultural power's context. Heilongjiang Research on Higher Education, 2012, (11), pp. 22-24 (In Chinese).

[18] S. D. Liu \& Y. R. Yang. From cultural quality education to cultural prosperity strategy. Journal of South China University of Technology (Social Science Edition), 2008, vol. 10(5), pp. 59-63) (In Chinese).

[19] X. Y. Wang. Discussion on motivation of cultural power in private college. Jiangsu Higher Education, 2010, (1), pp. 46-49 (In Chinese).

[20] S. J. He \& G. X. Liu. Examination and construction of university cultural strength. Journal of Higher Education, 2010, vol. 31, pp. 1-8 (In Chinese).

[21] H. L. Ding. Reflection on research cultural power in college. China Adult Education, 2011, (1), pp. 34-38 (In Chinese).

[22] H. J. Hu. Promotion effect of universtiy city cultural power on the formation and development of economics in the new are. Business Are, 2010, vol. 34, pp. 118-119 (In Chinese). 
[23] Y. R. Yang \& S. D. Liu. Cultural power is the competitive soft power for prestigious college. Higher Education Exploration, 2009, (1), pp. 37 40 (In Chinese).
[24] Q. Hu. Collegiate cultural power and culture construction in Zhejiang Province. Education Review, 2013, (4), pp. 108-110 (In Chinese). 